Revista Iberoamericana, Vol. LXXIII, Núm. 218, enero-marzo 2007, 259-274

\title{
LA CRISIS DE REPRESENTACIÓN EN TRES NOVELAS CUBANAS: LA NADA COTIDIANA DE ZOÉ VALDÉS, EL PÁJARO, PINCEL Y TINTA CHINA DE ENA LUCÍA PORTELA Y LA ÚLTIMA PLAYA DE ATILIO CABALLERO
}

POR

NAnNe Timmer

Universidad de Leiden

En el presente artículo quisiera comentar la específica relación que existe entre la narrativa cubana contemporánea y el posmodernismo. Estos apuntes surgieron de una investigación de doctorado sobre la reciente novelística cubana, en el marco de un proyecto colectivo titulado "Posmodernismo e identidad cultural en literaturas occidentales". ${ }^{1}$ Para elaborar la idea del fin de los grandes relatos en la narrativa cubana se hace preciso describir la relación entre el relato nacional cubano y el posmodernismo, y verlo luego en relación con el contexto cultural de los noventa, que fue en el que aparecieron las tres novelas de las que me ocupo aquí: La nada cotidiana de Zoé Valdés, El pájaro, pincel y tinta china, de Ena Lucía Portela, y La última playa, de Atilio Caballero.

El término posmodernismo se ha venido aplicando a un período cultural de fines de siglo xx, a mecanismos técnicos en el arte (el juego paródico, el pastiche, la fragmentación, la indeterminación, lo carnavalesco y lo metaficcional entre otros) y a una actitud de desconfianza hacia los valores legitimadores de la Modernidad. El último aspecto en particular suscitó mucha discusión en los ochenta porque críticos como Jameson y Habermas vieron en el descrédito posmoderno de los “grandes relatos”, y en su revalorización de la diversidad, en realidad un uniforme capitalismo globalizador. La polémica se hizo más compleja en relación con la situación latinoamericana, donde se hablaba frecuentemente de la traumática relación con la modernidad en la historia del continente. El debate latinoamericano estuvo marcado por realidades en las que la pobreza y la desigualdad social estaban al margen del desarrollo económico de los centros de poder, y la crítica se mostró escéptica para aplicar el concepto posmodernidad a un continente no completamente integrado en la modernidad. Hubo, sin embargo, también voces que vieron en el 'pos' un positivo 're' que se prestaba para redistribuir relaciones de poder, revisiones, reescrituras y cuestionamientos de la identidad definida desde el poder.

\footnotetext{
${ }^{1}$ Una primera versión en inglés de este ensayo será publicada en un volumen sobre Postmodernismo e identidad cultural en literaturas occidentales editado por Theo D'Haen y publicado por Rodopi, que recogerá los resultados de cada uno de los integrantes del grupo de investigación del Onderzoeksschool Literatuurwetenschap (OSL).
} 
EL RELATO NACIONAL

En Cuba se vivió el mismo debate a fines de los ochenta. Lo inició la revista Casa de las Américas -la primera en el ámbito latinoamericano en publicar el artículo de Fredric Jameson-. Dos temas polémicos emergieron en la discusión: 1) el así llamado fin de la historia y 2) el interés por los márgenes que propagaba el posmodernismo.

En cuanto al primero, la falta de conciencia histórica del posmodernismo y su diferente concepción del tiempo como una sucesión de momentos inconexos, se oponía a la visión del materialismo histórico dentro del discurso revolucionario. Si la Revolución decía legitimarse a través de la historia, la falta de conciencia histórica era, a todas luces, algo contrarrevolucionario. Así opinaba el ministro de Cultura, Abel Prieto, en 1992, cuando decía:

Poco después, se harían predominantes en el pensamiento y en la creación artística diversas tendencias de raíz derechista más o menos evidente, que se expresarían de mil maneras: desde las más elaboradas fórmulas culturológicas hasta el lenguaje rutilante y pueril de la televisión. Sabríamos luego que todas esas tendencias estaban tejiendo un discurso poderoso y de pretensiones totalitarias: el discurso posmoderno. (133)

La revolución institucionalizada se manifestó al inicio como uno de los voceros más escépticos del posmodernismo, lo cual no sorprende porque modernidad y revolución son palabras intrínsicamente relacionadas. En el relato nacional cubano se había creado una versión esencialista de la historia para consolidar la identidad nacional. Los héroes nacionales fueron situados en una línea genealógica con José Martí, “nuestro apóstol”, en el origen de las ideas, y con Ernesto 'Che' Guevara como símbolo del futuro en su personificación de “el Hombre Nuevo”. También el tiempo adquirió su propio simbolismo, con una era paralela donde 1959 se corresponde al año cero, y según la cual en el presente nos ubicamos en el año 47 de la Revolución. Esto nos recuerda a Walter Benjamin, quien describe en la tesis XV que el calendario de la Revolución no cuenta el tiempo en horas, sino que lo convierte en un monumento de conciencia histórica (701-702). Múltiples ejemplos de estos mecanismos se encuentran en las aperturas y los cierres de los discursos de Fidel Castro. Véase, por ejemplo, el siguiente:

Compatriotas: La historia ha probado que nada ha podido derrotar a nuestro pueblo en sus nobles afanes de lucha, y que las armas físicas no son más poderosas que las ideas. Gómez y Maceo, su tenacidad y su heroísmo, cabalgan hoy jinetes invictos por nuestros campos; Céspedes y Agramonte llevan consigo la Constitución y la justicia por la cual derramaron su sangre en la república soberana y libre que proclamaron en 1868. Reina el pensamiento de Martí en el pueblo de trabajadores que somos hoy, y nada pudo tampoco impedir que del espíritu proletario de un país que fue construido durante siglos con sangre y sudor de esclavos y obreros, brotaran con fuerza inextinguible y para siempre el ansia más plena de libertad y toda la justicia que demandó nuestro Héroe Nacional: el socialismo. Lo que hoy somos lo hemos sabido defender con honor y con un espíritu de humanidad y justicia que, como fuego eterno, es ya inapagable. ¡Gloria en especial, este 26 de Julio, a los que un día como hoy, hace 49 años, derramaron su sangre y entregaron 
sus vidas para iniciar de nuevo, con siempre creciente conciencia, el camino que aquellos emprendieron! ¡Gloria al pueblo que, educado en ideas justas y tradiciones heroicas, las ha mantenido hasta hoy, las mantendrá mañana y hasta la victoria siempre! ¿Qué somos y qué seremos sino una sola historia, una sola idea, una sola voluntad para todos los tiempos? [...] ¡Viva el socialismo! ¡Patria o Muerte! ¡Venceremos! [Apertura y cierre del discurso pronunciado por Fidel Castro, por el $49^{\circ}$ aniversario de los asaltos a los cuarteles Moncada y Carlos Manuel de Céspedes, el 26 de julio de 2002]

El fragmento muestra cómo los héroes nacionales del siglo xix siguen cabalgando en tiempo presente por los campos cubanos. Un presente eterno, creado y recreado en el discurso, adquiere sentido a través del recuerdo. Cada año tiene su propio nombre; en cada fecha se conmemora otro evento histórico. Por medio de la repetición de palabras abstractas al inicio y cierre de los discursos, por medio de figuras retóricas y asociaciones católicas en la palabra "gloria”, se modela una identidad colectiva con una esencia ("una sola historia, una sola idea, una sola voluntad para todos los tiempos”). A través de la ritualización el lenguaje relega a un segundo plano su función comunicativa para convertirse, sobre todo, en un código de grupo donde el "nosotros" revolucionario se opone a un "ellos" contrarrevolucionario. Estos mecanismos recuerdan mucho algunas de las características del populismo latinoamericano, resumidas por Santiago Castro Gómez, quien entre otras menciona: "la idea de que el mal se encuentra fuera de la nación”, "la oposición radical entre lo auténtico y lo foráneo”, "la postulación de una especificidad cultural latinoamericana”, "la invocación al sentimiento religioso y al mesianismo político”, "la exaltación del paternalismo intelectual y el liderazgo carismático”, “el culto a los héroes” y "el recurso a lo popular como instancia legitimadora de la verdad” (70). El posmodernismo no sólo parecía quitarle al discurso revolucionario el arma de la historia, sino también el futuro. Con el llamado "fin de los grandes relatos" (Lyotard) o el "fin de la historia” (Fukuyama), no se reconocían los futuros alternativos. ¿Qué quedaba si se sacrificaban los sueños en un mundo mejor, si no se creía en valores como la emancipación y el progreso lineal del pensamiento moderno de la Ilustración? Eran precisamente estos los valores con los que se legitimaba la Revolución Cubana de 1959.

En cuanto al segundo punto, el interés posmoderno por los márgenes, las reacciones tampoco fueron demasiado entusiastas. Diversos críticos dejaron en claro que el interés por la periferia era bienvenido, pero que no aportaría mucho si las relaciones internacionales de poder no cambiaban. Gerardo Mosquera expresó el peligro de que los artistas latinoamericanos se comportaran como objeto exótico para el Primer Mundo. Con la sed de la diferencia y el exotismo por parte del ‘Occidente', el discurso posmoderno ponía en peligro otra arma de la lucha emancipatoria: la noción de la identidad propia y la 'diferencia' de la periferia, convirtiéndola en artículo de consumo del primer mundo. La izquierda institucionalizada, y Cuba, como ícono latinoamericano del posible sueño en un mundo mejor, se vería sin historia, armas, ni futuro, si no formulaba una respuesta al discurso posmoderno. 
OTRAS VOCES EN LOS AÑOS NOVENTA

Aparte de las voces institucionalizadas, surgen muchas otras en el circuito cultural de la isla. Fue sobre todo a fines de los ochenta e inicios de los noventa cuando múltiples artistas expresaron, en un lenguaje directo y provocativo, su frustración sobre las relaciones de poder en el país. Tuvieron lugar encuentros entre artistas e intelectuales que estaban moldeando discursos alternativos. Los primeros artistas trataron temas socialmente delicados por medio de performances, obras de teatro o el arte plástico. Grupos como Castillo de la Fuerza, Hacer, TTVV, Arte Calle, Pilón y Paideia son ejemplos de los viveros de voces alternativas, algunos de los cuales son ubicadas dentro de lo posmoderno por Margarita Mateo. En los intercambios intelectuales y artísticos organizados en nombre del proyecto Paideia se presenciaron debates sobre las relaciones entre el intelectual y el poder, a través de lecturas de pensadores como Foucault y Deleuze. Como explica Ernesto Hernández Busto, uno de los iniciadores de Paideia, "el discurso posmoderno vino a ocupar el lugar de un pensamiento disidente”; y a su vez, "la curiosa paradoja según la cual la posmodernidad conseguiría igualar la realidad política cubana con los ámbitos teóricos de las exhaustas democracias occidentales tenía mucho de pirueta generacional”. Entrando la década de los noventa, después de la caída del muro de Berlín y con la desintegración de la Unión Soviética y la consecuente escasez de productos alimenticios, cambió la situación. El gobierno ajustó el espacio de expresión de dichos grupos por medio de sanciones directas o indirectas, y a mediados de los noventa la comunidad artística e intelectual de la isla se encontró más fragmentada y dispersa debido también al flujo de personas al extranjero. El debate posmoderno fue retomado por la crítica literaria en revistas como Temas y La Gaceta de Cuba. Pero, sobre todo revistas ‘underground' como Diáspora(s) y, más tarde, Cacharro(s), siguieron en la línea inconforme de inicios de los noventa, usando a escritores como Deleuze y Foucault, e intentando romper activamente el monólogo cultural institucionalizado.

La crítica literaria cubana comienza a hablar una y otra vez sobre la literatura inconforme de los escritores novísimos cuando los años más agudos y críticos, en cuanto al diálogo entre estado y arte, ya habían pasado. Aun así seguían sin conseguirse determinados textos y muchos escritores de esa generación se habían marchado al extranjero. Desde ese momento le tocó a la crítica apropiarse de la inconformidad de aquellos textos. Los críticos literarios se interesaron por la generación de escritores nacidos con la Revolución, a quienes se llamó los “novísimos”, y a los más jóvenes, los "posnovísimos" (Redonet). Las peculiaridades de los textos producidos por ellos se mostraron en una actitud rebelde al romper tabúes, en el predominio de lo marginal, y en la desmitificación de grandes valores del sistema (Redonet). También a nivel textual los críticos vieron una innovación en la fragmentación de la estructura, en el tono lúdico y en la escritura misma como tema (Redonet). El hecho de que estas características tengan mucha relación con lo que internacionalmente fue llamado "posmoderno” (cf. Hassan, Hutcheon y McHale), también fue observado por Margarita Mateo, quien en su estudio Ella escribía Poscrítica, vio posibilidades de interpretar el posmodernismo como una diversificación positiva y una actitud continuamente rebelde. La forma original en la que presenta su estudio lo acerca a la literatura actual: el libro juega con la disolución de los 
géneros al intercalar entre los capítulos críticos textos lúdicos y autobiográficos sobre el acto de escribir mismo.

La mayor parte de los estudios literarios de la literatura cubana contemporánea tratan el cuento ‘novísimo’ y ‘posnovísimo’, mientras que prácticamente nada se escribió sobre la novela, de la que se publicó menos por la escasez de papel que afligió la isla al inicio de los noventa. En la segunda mitad se publicaron más novelas, en parte gracias a las editoriales extranjeras. Desde 1993 se facilitó el trámite con los mercados extranjeros al despenalizarse el dólar y al permitir la ganancia de royalties. Al mismo tiempo, las editoriales extranjeras comenzaron a interesarse por la venta de los relatos de la "auténtica experiencia cubana”(Whitfield). Los cambios socioeconómicos hicieron estallar polémicas en revistas cubanas sobre la fricción entre arte y comercio; algo que tenía mucha tradición en la isla. También dentro de la ficción la relación (“comercial”) entre cubano y turista se convierte en tema literario, por ejemplo en “La causa que refresca” de José Miguel Sánchez (Yoss), que se centra alrededor del "turismo ideológico" (Portela). En un monólogo interior, podemos ver cómo el "guía” cubano parece estar vendiendo sus rasgos exóticos al extranjero:

Yo soy lo que soñaste todos estos años, justamente lo que buscas. Tengo ojos mestizos y la piel mordida por el sol y el salitre, pelo indómito y músculos de trabajo y no de gimnasio. O lo que queda de esos músculos, porque, como bien sabes, la situación está dura. Tengo cara de intelectual autodidacta y partyman, todo en una sola pieza. Natural, encantadoramente medioharapiento. ¿Lo ves? En mis facciones está el peligro, el delicado riesgo del robo o la enfermedad venérea pero también la dulzura de la caña, la sincera amistad, el buen salvaje de Rousseau. Bienvenida. Sí, yo seré tu guía. (241)

De manera lúdica, los textos de esta generación de escritores tratan temas social y políticamente delicados. No todos los textos, sin embargo, son tan referenciales. El rasgo principal de la literatura reciente es su gran diversidad, y aunque la crítica la coloque dentro de una misma categoría (como posmoderna, posnovísima o novísima), los rasgos textuales de las novelas de la década no coinciden tanto entre sí. Dentro de la diversidad, sin embargo, se veían ciertas constantes: la desmitificación de los grandes valores del sistema, el predominio de lo marginal, lo escatológico, del cuerpo, y particularmente algo que muchos críticos sólo mencionaron, pero que no elaboraron: el tema de la subjetividad.

\section{De LA SUBJETIVIDAD Y EL LENGUAJE}

Algunos críticos cubanos observaron un desplazamiento desde lo colectivo hacia lo individual (Mateo, Redonet). La pregunta ya no era tanto “quiénes somos”, como en los sesenta, sino “quién soy”. También en otras disciplinas se comenta esta tendencia. En la revista Temas el psicólogo Fernando González Rey expone abiertamente el problema de la subjetividad y aboga por una interacción más diferenciada, ya que observa la falta de espacio para la expresión de opiniones individuales y la dependencia de la gente de un discurso oficial demasiado homogéneo (95-96). Cuando el tema de la subjetividad comenzó a ser uno de los principales en mi investigación surgió la necesidad de profundizar en la problemática. La hipótesis inicial que unía los términos posmodernismo 
e identidad cultural se desplazaba cada vez más a la relación entre sujeto y representación. Allí residía la respuesta a la incompatibilidad de los conceptos posmodernismo e identidad, y a la diversidad de textos que hacían llamarse posmodernos.

La palabra sujeto se usa para referir al sujeto gramatical de una frase, lo cual hace sospechar una cierta autonomía de la persona que está en el origen de la acción y que crea la impresión de una esencia identitaria “subyacente” en las cosas. Etimológicamente, sin embargo, el verbo subiicere, que significa "someter” o "poner debajo”, apunta hacia otra dirección. Aquella instancia que actúa es al mismo tiempo aquello atado y dominado por las mismas cosas debajo de las cuales yace. Michel Foucault aclara que hay dos niveles de los que puede estar sujeto el individuo: 1) de otra persona por control o dependencia y 2) de su propia identidad por conciencia y autoconocimiento (212). El individuo, entonces, no es tan autónomo como sugerí antes y no se encuentra fuera de las relaciones de poder que lo reprimen. No, el individuo es más bien construido dentro de los procedimientos de sumisión; es por su conocimiento también sometido a su propia identidad. La idea de que la conciencia linguística no se puede ver desligada de las relaciones de poder está más elaborada por Giorgio Agamben. Él explica que la palabra "vida” tiene dos orígenes diferentes en la tradición griega. La palabra “zoé” expresaba el simple hecho de vivir, común a todos los seres animados (también dioses, plantas y animales), y "bíos” indicaba la forma o manera de vivir propia de un individuo o de un grupo (9). Lo decisivo de la política de la modernidad es para Agamben "el ingreso de la zoé en la esfera de la polis, la politización de la nuda vida como tal”, para lo cual destaca la relevancia de los estudios de Foucault (Agamben 13). El filósofo explica que el paso entre el simple hecho de estar vivo (zoé) y una forma de vida específica es el mismo paso que el de la voz al lenguaje, aquello que distingue al humano de los animales. Allí donde se usa el lenguaje existe la posibilidad de darle forma a la "nuda vida” dentro del espacio político, y se llegaría a una forma de vida que se distinga del simple hecho de vivir. Así explica Agamben que existe la política porque el humano es el ser vivo que, a través del lenguaje, se separa y se distancia de la vida desnuda, pero que al mismo tiempo sigue conectado con ella (12). Esto ocurre, entre otras cosas, porque el individuo está sujeto a su propia identidad a través del lenguaje, como ya indicó Foucault. La misma relación compleja entre lenguaje y sujeto está elaborada por el psicoanálisis. Jacques Lacan deja en claro que el yo no existe detrás del lenguaje, sino que se construye dentro de él. Por eso siempre está fuera de sí, siempre está en proceso y nunca es un producto fijo.

Me identifico en el lenguaje pero sólo perdiéndome en él como objeto. Lo que se realiza en mi historia no es el pretérito definido de lo que fue, puesto que ya no es; ni siquiera el perfecto de lo que ha sido en lo que yo soy, sino el futuro anterior de lo que yo habré sido para lo que estoy llegando a ser. (Lacan 299-300, traducción mía)

Estas reflexiones nos dejan ver que la noción de identidad es una construcción linguística en la cual la carga ideológica y las relaciones de poder diseñan las posibilidades del ser. Así, observa Foucault que ante el problema de la libertad no se trata de "liberar el individuo del estado, y de las instituciones estatales, sino de liberarnos tanto del estado como del tipo de individualización ligado al estado” (216). En este proceso se subraya la 
lucha "contra aquello que ata el individuo a sí mismo y a otros de la misma manera”; son "luchas en contra de sometimiento y contra formas de subjetividad y sumisión” (212). El desplazamiento de lo colectivo a lo personal anteriormente mencionado no es tan simple como parece a primera vista, porque lo último está creado dentro de un colectivo. Si tomamos en cuenta las reflexiones anteriores, también vemos que la noción de identidad ha cambiado mucho en el pensamiento contemporáneo. En la "crisis de los grandes relatos”, como llama Lyotard a la condición posmoderna, el yo también es un gran relato, el del sujeto cartesiano. Ya no se puede hablar de un sujeto coherente, sino de un yo fragmentado que tiene infinitas posibilidades en el lenguaje. Incluso la identidad individual es una construcción de un todo. El yo está compuesto de un número infinito de fragmentos desconocidos que se resume en la totalidad “yo". La crítica cubana Margarita Mateo sugiere que en el posmodernismo ya no se trata de la preocupación por la definición de la identidad personal, sino de un ser temporal, de un estar;

[...] leído al revés, el yo soy yo [...] se convierte en un oy yo soy, así, sin la hache de Horacio. Un oip que podría asociarse, por una parte, a la urgencia de presente del posmodernismo, pero también a la difuminación de la identidad. Hoy yo soy. Ya es bastante. Mañana también seré, probablemente, pero no sé cómo. No tengo por qué ser quien fui hoy, no tienen por qué coincidir las identidades. (44)

$\mathrm{Al}$ reconocer la crisis de los grandes relatos, el yo se convierte en sus fragmentos y surge la posibilidad de reorganizar los fragmentos más marginales del yo. La consecuencia de estas reflexiones es que toda noción de identidad es una construcción lingüística. Sólo quedan los deícticos ego, hic, nunc (yo, aquí, ahora) como un esqueleto de identidad que se organiza dentro de una red de mecanismos políticos y sociales del lenguaje, pero que refieren a algo fuera del lenguaje, no representable, que coincide con la 'vida desnuda' (zoé) de la que habla Agamben. Los tres deícticos tan aparentemente insignificantes llevan a abismos filosóficos y al silencio si queremos estudiar su función. Analizo a continuación la relación entre ese punto cero de la existencia, no-verbal e intangible, y la vida política en tres novelas cubanas de los noventa. Respeto el rasgo principal de la narrativa reciente: su diversidad. Tres novelas muy diferentes entre sí hablan de la relación entre el lenguaje y el vacío detrás de las palabras, o entre vida política y vida desnuda. Siguiendo lo anterior, organizo estas lecturas alrededor de tres ejes deícticos (yo, aquí y ahora).

\section{Yo}

La primera novela, La nada cotidiana de Zoé Valdés, se publica en 1995 fuera de Cuba y es la primera en una serie de "novelas del período especial” (Whitfield) que narra la experiencia cubana de los noventa para un lector implícito extranjero. Es una especie de testimonio que sigue el modelo de la autobiografía de Reinaldo Arenas. Carlos Victoria llama este género de texto "literatura de urgencia”, y explica que es una mezcla entre testimonio y autobiografía en una narración provocadora en primera persona (citado en Serrano). El hecho de que La nada cotidiana fuera provocativa, se notó en diversas reacciones de los reseñadores. Si al lector no le chocaba el lenguaje contrarrevolucionario, 
sí lo harían las escenas explícitamente eróticas en el texto, además narradas por una mujer. Otro aspecto espinoso era el hecho de que una escritora no muy conocida se hiciera famosa con el éxito comercial de una obra que narraba la vida cotidiana en la Cuba de los noventa. Se expresaron fuertes juicios de valor dentro de la comunidad cubana acerca de la calidad de la obra, acerca de la autenticidad o del oportunismo de su testimonio. Precisamente por tales razones me parece relevante no descartar una obra que levantó tales pasiones entre los lectores. No me interesan los criterios de lo auténtico o de lo falso; en cuanto a lo autobiográfico, si bien existen algunas semejanzas entre la autora y la protagonista nacieron ambas el año de la Revolución-, éstas no son relevantes para mi lectura. Más interesante me parece estudiar el aspecto autobiográfico como un "modo de autodefinición o una expresión autorreferencial, que permite, inhibe el proyecto de autopresentificación, de convertir uno mismo en un presente prometido por el lenguaje” (Renza citado en Elbaz 11).

En un monólogo interior la voz crea un presente eterno mediante una narración lenta y simultánea donde casi no existe la acción. Los eventos no se distinguen entre sí y queda una 'nada cotidiana'. El mundo exterior está a millas de distancia y el recuerdo se infiltra en el tiempo presente. Mediante la narración retrospectiva y aquello que Dorrit Cohn llama “monólogo autobiográfico” (181), la narradora recrea el relato de su vida. El argumento se desarrolla sobre la figura de una muchacha que, nacida el mismo año que la Revolución, recibe el nombre de Patria. La novela crea un yo al desconstruir el sujeto Patria, del discurso revolucionario. A través del lenguaje se le da vida al individuo que como feto se encontró sepultado por los símbolos nacionales y colectivos, como El Che y la bandera cubana.

Antes de salir de la concentración multitudinaria, al pasar por delante de la tribuna, el Che le puso la bandera cubana en la barriga, pero ella apenas ni se enteró, porque yo seguía jodiéndola, provocándole unos dolores del carajo. Y Fidel continuaba con su arenga más verde que las palmas. Y yo dando cabezazos, codazos, tortazos, queriendo huir de su cuerpo, de todas partes. (21)

Cuando Patria se hace mujer, rechaza su nombre y opta por el de "Yocandra", donde se encuentran ecos de mujeres míticas como Casandra y Yocasta, como también señaló Jorge Fornet (40). En vez de ser nombrada, ella quiere nombrar. Por eso sólo leemos los apodos de los personajes que la rodean. Amigos como "La Gusana, "El Lince" y "El Nihilista” se contraponen a personajes como "El Traidor”, "La Macha Realista” y "La Militonta”. En estos juegos de palabras observamos una revaloración de lo que se consideraba femenino u homosexual, y una crítica al "macho-leninismo". Las características estereotipadas de personajes como el padre, un típico guajiro revolucionario, el traidor, su ex-marido, y Fidel Castro, llamado "quién tú sabes”, se superponen. La extrema devoción de la mujer y la decepción consecuente recurren en los tres casos, lo cual se explica si tomamos en cuenta que "en la sociedad socialista ha ocurrido un traspaso de poderes en el cual el patriarcado ejercido tradicionalmente por el Padre y el Esposo ha quedado ahora en manos del Estado" (Cámara 55).

Al desconstruir el sujeto, en el análisis de la obra se hacen visibles diversas dicotomías del discurso en el que se mueve el individuo: lo masculino versus lo femenino, 
lo personal versus lo colectivo, el adentro versus el afuera y la vida versus la muerte. Al re-escribirse, Valdés recoloca estas oposiciones. Al inicio de la obra la protagonista narra desde un yo aislado y alienado que no siente la vida. Esta enajenación recibe una carga política cuando Valdés coloca fragmentos del himno nacional "morir por la patria es vivir" dentro de otro contexto. Cuando más tarde afirma que "morir y vivir el mismo verbo", se intuye la inversión "vivir por la patria es morir”. La voz del yo se busca en un collage textual que combina dichos, consignas, aforismas, citas de escritores cubanos y jerga callejera.

El primer capítulo, el único narrado en tercera persona, cuenta la historia de una mujer nacida en una isla que quiso construir el paraíso. Este capítulo funciona como una miseen-abyme en tanto representa el estado de enajenación e inbetweenness de toda la obra. No se sabe si la protagonista está viva o muerta, ni si merece el paraíso o el infierno. A partir del capítulo dos comienza la narración del nacimiento y es la escritura la que intenta recrear, incluso definir el yo, salvarlo del estado de inbetweenness. Al escribir, la narradora intenta convertir el estado de enajenación en una identificación con el cuerpo. En escenas explícitamente eróticas, Yocandra nombra casi con agresividad las partes del cuerpo para apropiarse de él y del registro correspondiente del lenguaje. Al final de la obra la narradora muestra su decisión de no autocensurar las palabras que pone sobre el papel, de las que no sabe si "ella las escribe o si son ellas las que me escriben a mí” (171). Al terminar la obra con la misma oración con la que comienza "ella vino de una isla que quiso construir el paraíso”, en cursiva, la estructura se vuelve circular: el yo no es un producto concluido, sino que siempre está en construcción. Usando la tercera persona en esa frase y en el primer capítulo, deja en claro que las palabras construyen una identidad fuera de ella misma. Esto nos muestra la urgencia y, a la vez, la imposibilidad de convertir el cuerpo en palabras y encontrar un yo fuera de un marco político, ideológico y lingüístico.

AQUí

La segunda novela, El pájaro: pincel y tinta china, de Ena Lucía Portela, es de índole muy diferente. La trama es menos importante que el escribir mismo, que se presenta como un juego lúdico lleno de metaficción. Dentro de la tradición cubana, se podría decir que la novela sigue los experimentos neobarrocos de la obra de Severo Sarduy. La obra ganó el premio novela de la Unión Nacional de Escritores y Artistas Cubanos (UNEAC), en 1997, y después de publicarse en el mercado cubano fue lanzada al mercado español por la pequeña editorial Casiopea. Dentro del interés de parte de la crítica por los textos de los "novísimos” y "posnovísimos”, la obra de Portela se mencionaba frecuentemente en relación con "la fragmentación del texto", “la desmitificación de los grandes valores del sistema” y "la escritura misma como tema” (Redonet, Araújo).

El relato discurre sobre tres personajes, Camila, Fabián y Bibiana, quienes, sin saberlo el uno del otro, se enamoran de un cuarto personaje: Emilio U., casado con una francesa. Cuando avanza la historia, el lector descubre que Emilio U. es el supuesto autor de una novela llamada 'El pájaro: pincel y tinta china'. Las relaciones entre los personajes y la búsqueda de Emilio U., son los principales ejes dentro del relato. Más relevante que la trama, resulta la manera en que está narrada. La sugerencia de una mise-en-abyme en 
la que el personaje Emilio U. sería el autor de la novela que estamos leyendo, es cuestionable. Se confunde el mundo ficticio sobre el que narra la novela con el mundo desde el cual se narra. No sólo se trata de una duplicación del narrador, sino que el narrador es una instancia esquizofrénica que se hace visible en diferentes niveles textuales. El “yo” es al mismo tiempo un personaje secundario -femenino o masculino-, un testigo, pero también un narrador omnisciente. De esta manera él/ella ${ }^{2}$ juega con su credibilidad y se complica la relación entre ficción y realidad. Así ocurre por ejemplo que, después de un fragmento sobre la vida emocional de un personaje, haya un salto repentino a un narrador autoconsciente quien admite que su narración no es otra cosa que pura construcción: "Camila había llegado algo agitada y le había dicho: "Tuve un accidente”. A veces era feliz, a veces tenía accidentes, a veces las dos cosas. No escribía a su familia, ¿para qué? Mis personajes no tienen familia y no creo que la necesiten” (41-42). Aparte del salto repentino a la realidad extraficcional, también ocurre lo contrario: el yo-narrador pierde su capacidad de distinguir la ficción de la realidad y de repente vive dentro de uno de sus personajes. Él/ella se apropia de sus vidas ficciones, como en el siguiente fragmento donde un personaje tercero se convierte de vez en cuando en la primera persona:

Fabián reconocía en repetidas ocasiones que Camila no le tenía miedo y eso le gustaba, lo movía a tocarla de otro modo, sin el perchero. Algo como besar despaciosamente, con los ojos cerrados y el pelo suelto, una cosquilla ligera, rococó, el pecho casi plano de la sacerdotisa, cuya respiración era entonces audible, acompasada. Las manos de ella, muy poco lo que se espera sean las manos de una muchacha, se apoyaban en mi cabeza, fuertes, y buscaban empujarla hacia abajo, hacerla rodar. Y los labios, la lengua inusitadamente hábil y obediente, iban hacia abajo, [...] por un camino de caracol, húmedo, expectante, de nuevo tenso en el abdomen ahuecado y duro que Fabián adoraba y quería comerse. [...]. Ella gemía de placer aunque a mí no me gustara su voz y me empujaba todavía más, dejándome sin escapatoria, me empujaba hasta el vacío que yo temía porque allí habitaba lo cierto lo único cierto con todos sus olores y sabores y su hambre. El fin de la ilusión era abrir los ojos, sentir el peso de las piernas de la sacerdotisa como una cruz -exacto, una cruz de hierro- sobre mi espalda y continuar entre el desconcierto siempre renovado, la sensación angustiosa de ser víctima de mí mismo y los murmullos y ondulaciones de ella, hasta que se aflojaba, también despacio, la presión, yo alzaba la cabeza y veía como enfermo a una muchacha relajada y feliz que me decía hijo de puta. Fabián no podía evitar en esos momentos la acometida de una tristeza oscura [...] (25-26; énfasis mío)

La oposición entre lo personal y lo colectivo, que vimos en La nada cotidiana, no se encuentra en esta novela. Se trata más bien de un mundo aislado que no se piensa aislado. En una sugestión solipsista el yo es un espacio sin forma donde conviven diferentes voces. El espacio entre el yo y el otro es difuso. Donde La nada cotidiana todavía buscaba definirse, esta novela juega ser una cosa y otra al mismo tiempo. La voz se duplica a sí misma infinitamente para que no se pueda así identificar el lugar desde donde habla. En el fragmento siguiente el “yo” deja ver que éste es un juego consciente:

${ }^{2}$ Tal como en la obra de Severo Sarduy, quien construye personajes dobles de dos géneros, el narrador en El pájaro: pincel y tinta china es también ambiguo. 
Ella [Camila] ignora, de más está decirlo, que ya Lacan, el pesado, el que seguro también tenía a alguien que le dijera "No seas así", se apareció un buen día con una linda y acabada teoría sobre la escisión del sujeto, sin la cual el lugar desde donde se habla sería apenas un misterio. A veces sigue siendo un misterio o, al menos, lo pretende. Por ejemplo, si adivinas quién soy yo, te doy un premio. (139)

La escritura se presenta como juego donde es posible ser narrador y personaje, pensar y actuar, y habitar todos los espacios posibles al mismo tiempo. Se crea un espacio virtual que no se limita a un cuerpo sólo pero donde el yo vive, a un tiempo, nowhere y everywhere. En esa visión de la identidad el yo no se distingue del otro. La novela crea libertad dejando que el sujeto se ubique en un sinnúmero de fragmentos y no lo reduce a un cuerpo, personaje, definición o característica. Pero no es sólo el tema de la libertad el tratado, sino sobre todo su contrapartida: el tema del poder y la dependencia resulta central en las relaciones entre los personajes. En los diálogos entre Emilio U. y Fabián, por ejemplo, Fabián se queja del hecho de que sólo es un personaje y que tiene autonomía sobre su habla. El narrador parece disfrutar de su omnipotencia en cuanto a su ficción, casi como el héroe sádico descrito por Sarduy, que "como un actor que, entre bambalinas, espera una imagen, la pronunciación de una palabra, una luz, para adentrarse en el espacio de lo abierto, de la Mirada, del Otro, así el héroe sádico espera, en el ensayo orgiástico de cada noche, la formación de esa escena en que la realidad será el dibujo de su deseo” (Sarduy 14).

Con tono provocador, Portela juega con los límites de lo decible. A primera vista parece no haber muchas referencias a la Cuba contemporánea, pero en los márgenes de la anécdota principal se suceden múltiples chismes o provocaciones en boca de 'otros'. Ese cacareo lúdico-palabras que a primera vista parecen no tener peso-contiene provocaciones al discurso revolucionario y a la sociedad literaria habanera mediante la alegoría y la sátira. Anécdotas alegóricas sobre la dictadura de Dr. Schilling en el hospital donde se encuentra uno de los personajes hacen pensar en referencias a la situación política cubana. Portela desafía la censura jugando con todo lo que podría decir y no dice.

\section{AHORA}

La tercera novela, La última playa, de Atilio Caballero, ganó el premio UNEAC de novela en 1998. Después de haber sido publicada por Unión, aparece un año más tarde en el mercado español gracias a la editorial Akal Literaria. Dentro de la tradición cubana, el aire mítico del relato recuerda la obra de Alejo Carpentier. Mito o no, la obra está inspirada en la realidad, como me informó el autor. Con tono documental se usa la información de tres testigos para reconstruir la vida de Simons, un ermitaño residente en la isla Cayo Arenas. La imagen con la que abre el libro es la siguiente:

Entre las olas se movía un cuerpo. Flotaba. Era el cuerpo de un ahogado, a unos cien metros de la costa. El viento, soplando desde el mar, lo empujaba despacio hacia el arrecife (15). El mar lo había devuelto al mismo lugar que una semana atrás eligió para sumergirse. Pero, ahora como antes, tampoco habría ninguno para recibirlo. En ese lugar donde su cabeza chocó contra el diente de perro ya no quedaba nadie. Ni nada. (16) 
Después sigue en flash-back la vida de Simons hasta el momento en que desaparece en el mar, al final del relato. En vez de una reconstrucción objetiva, el narrador se toma la libertad de diseñar la vida, el tiempo y las percepciones de Simons mediante una narración simultánea. El protagonista entrega toda su vida para salvar la isla Cayo Arenas de la erosión. Todos los días ata cuerdas a los árboles inclinados a la orilla del mar, para erguirlos. Todos los días pinta las fachadas de las casas tal como eran en el pasado sobre superficies de cartón a tamaño natural. Lucha en contra del tiempo, el olvido y contra el irremediable destino de la muerte. Sabe que la isla será tragada por el mar, pero considera suya la tarea de mantener vivo el recuerdo. Las imágenes apocalípticas, según avanza la narración, intensifican el aire mítico. Según Mircea Eliade, el mito es "una historia sagrada” y "relata un evento que tomó lugar [...] en los inicios del Tiempo (5). "El mito narra [...] cómo surgió una realidad, y puede ser la completa realidad, el Cosmos, o sólo un fragmento de ella - una isla, una especie de planta, un determinado tipo de comportamiento humano, una institución [...]” (Eliade 5). También son mitos aquellos que tratan el fin del mundo, como el de La última playa, porque "para que surja algo genuinamente nuevo, los vestigios y las ruinas del ciclo antiguo tienen que haber sido destruidos completamente” (Eliade 51).

Un lugar donde no existe nada ni nadie es la imagen del inicio y del final del libro, cuando Simons se entrega al sinsentido de sus proyectos. Paradójicamente experimenta goce y alivio cuando descubre esto. Uno de los temas principales del relato es la transformación de la lucha en contra de la muerte en una aceptación de ella. En la evolución del personaje principal vemos que éste cambia la perseguida trascendencia por un momento de felicidad. Al principio Simons todavía se aferra al simulacro de identidad de la isla, mientras que al final abandona también esto.

La estructura narrativa va pareja al tema. Mediante la narración simultánea se crea un presente eterno; al combinar determinaciones como "hoy" o "ahora” con el tiempo pasado, el narrador crea la impresión de querer encontrar un presente donde el pasado se deja ver con demasiada insistencia. Sólo en una página de todo el libro se narra en un tiempo verbal del presente. Es el momento en que el anciano se encuentra con una muchacha y es además el momento que Simons recordará como el evento más importante al final de su vida. La narración sugiere que sólo entonces el protagonista vivía el presente.

El relato mítico contiene ecos de historias universales -Sísifo, Robinson Crusoe, Dédalo o la desaparición de Atlantis-, pero además tiene relación con el contexto cubano. Uno de los sueños de Simons es la construcción de un puente que una la isla con tierra firme. En los cuatro intentos de la construcción, los obreros tienen que dejar su trabajo debido a un evento importante en la historia cubana. Ya a finales del siglo xIx alguien había hecho el intento, pero no pudo concluir su trabajo debido a la pasión y al "frenesí" que despertó “el nacimiento de la república” (33). El protagonista sigue este proyecto en 1933, pero tiene que dejar la empresa por el caos nacional en el verano de ese año, cuando tomó lugar una de las primeras revoluciones cubanas del siglo xx, contra Machado. Años después, Simons retoma el proyecto con la ayuda de muchos obreros, pero:

[...] un buen día todo se paralizó. Los ayudantes no llegaron, los barcos tampoco. Por una semana no tuvo noticias exactas de lo que sucedía. Era extraño. Parecían tan entusiasmados 
como él. Los pocos habitantes que quedaban en el cayo regresaron a la ciudad, o se esfumaron. Diez días después, cayendo la tarde, recaló el mecenas en un bote de remos. -Llegó la convulsión. Recoge los palos que se acabó el puente.

Simons no pudo entender las palabras del mecenas. Ni por qué volvía a marcharse con tanta prisa, gritando todavía desde el agua que se cuidara de los sueños, no los fuera a esconder entre la madera ahora que todo era propiedad social, mientras se reía como un demente remando desaforado hacia la boca de la bahía. (56)

En esta cita vemos la referencia a la Revolución de 1959. Años después resurge el entusiasmo por terminar el puente con la ayuda de “camaradas extranjeros”, "ingenieros” "rubios", a quienes les gustaba el "vodka”. Pero ellos tienen que volver a su isla y Simons se queda de nuevo solo con los materiales; la referencia a la desaparición del apoyo económico de la Unión Soviética y el inicio del "período especial” es transparente. La historia del anciano y Cayo Arenas está al margen de una historia nacional donde los grandes proyectos políticos reclaman toda la atención del país a costa de iniciativas alternativas y menores. El sueño de Simons, al mismo tiempo, tiene semejanzas con la utopía revolucionaria. Ambos siguen el sueño que un cubano soñó durante la lucha independentista, y ambos construyen algo mayor que trasciende el presente.

La trama no sólo relata sobre una historia marginal, sino que adquiere una función alegórica al combinar el aislamiento del protagonista con el aislamiento del cayo, de Cuba y de su situación política. Mediante la descripción de la naturaleza como si fuera una parte de Simons, se crea una simbiosis entre el hombre y la isla. Ese sujeto isla está hecho por la dicotomía adentro versus afuera, tal como existe en el discurso revolucionario: "dentro de la Revolución todo, contra la revolución ningún derecho” (Castro). El relato deshace esa oposición y, de esta manera, desconstruye el sujeto isla. El protagonista descubre al final de su vida que todos sus esfuerzos fueron en vano porque desde siempre había existido un camino olvidado, bajo el agua, que unía la isla con tierra firme. En aquel momento él no sólo se despide de sus proyectos y de su vida, sino también de la identidad imaginaria de la isla creada a través de la retórica del recuerdo. Se entrega a lo que es en aquel momento sin construir su identidad en un relato. La novela narra el intento de deshacer el ahora de una carga simbólica que le es dado por el discurso moderno, y revolucionario en este caso. Encontramos este mismo tema en textos de otros escritores cubanos contemporáneos. Antonio José Ponte se refiere al discurso revolucionario como "una apariencia aplastante de eternidad, de temporada muerta, de canícula” (27) y José Manuel Prieto se pregunta si "es válido hipotecar el presente en aras de un futuro u-tópico, es decir, perseguir un no-lugar sin un ahora?” (78).

\section{CONCLUSIÓN}

Donde la primera novela buscaba un yo, la segunda un aquí, la tercera busca un ahora desligado de la carga ideológica de la retórica revolucionaria. Estos tres textos, tan diferentes entre sí, tienen en común una desconstrucción de la identidad que gira alrededor de un vacío. La nada cotidiana muestra el vacío ya en el título, y lo relaciona con un “exceso de vida obligatoria”. En El pájaro: pincel y tinta china el narrador es voyeur, “un 
espía de la nada” que borra el lugar de enunciación para transformar el aquí en ficción. De ese modo finge no ver lo cotidiano, mientras que el espacio muerto y vacío donde ya no existe nada ni nadie es precisamente el interés central de La última playa.

El tema subyacente de los límites existenciales entre vida y muerte, y entre zoé y bios, como expliqué en el cuadro teórico, se hace visible en estas novelas de maneras diferentes. En La nada cotidiana el individuo se encuentra entre la vida y la ese modoomnteapeso, contienenmuerte, y en El pájaro: pincel y tinta china en un solipsismo que se desplaza de la existencia de uno para apropiarse de la existencia del otro. La última playa narra un fin de los tiempos que hace espacio a la pregunta de qué es la vida y qué es la muerte. Esa escritura apocalíptica apunta hacia un vacío donde se encuentra el eje de la subjetividad, la zoé o "la nuda vida”. Allí es donde termina y se inicia el habla, detrás de los deícticos. Ese espacio desconocido e inasible rechaza la identidad colectiva del discurso revolucionario, donde el presente está al servicio de algo más trascendente. Una de las voces a la que Rolando Sánchez Mejías cede la palabra en un ensayo polifónico expresa el mismo vacío cuando resiste la tentación de captar el futuro de Cuba en palabras:

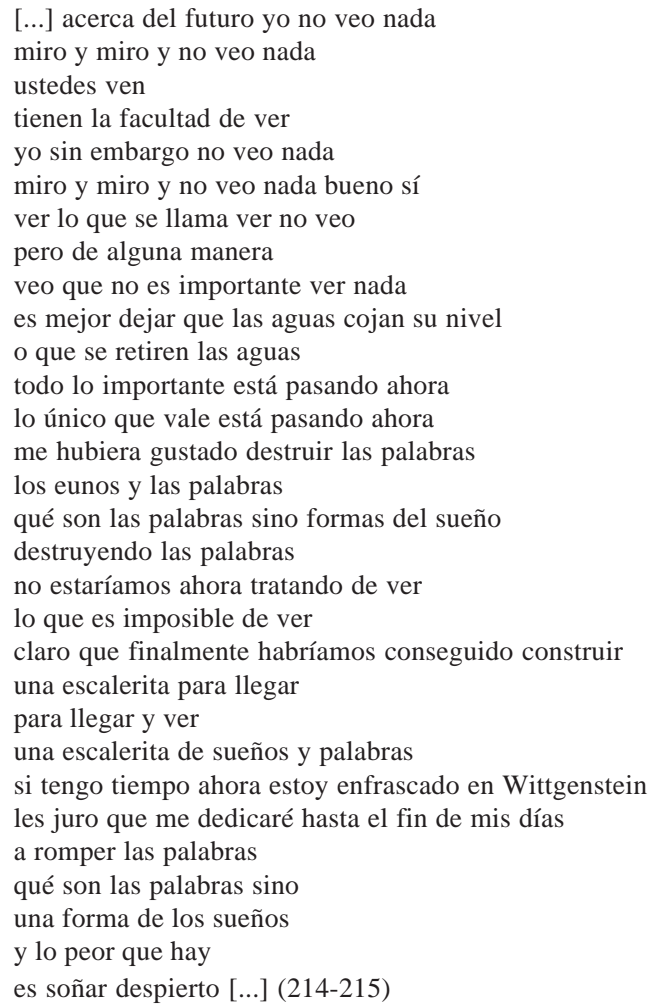


Son tantas las palabras sofocadas por las retóricas de los discursos revolucionario y contrarrevolucionario, que no queda lenguaje para la reflexión. El ensayo "Reunión” de Sánchez Mejías, que intenta dar respuesta al qué pasará en "Cuba, el día después...”, vuelve al punto cero de la representación en cuanto a forma y contenido. Él subvierte el género del ensayo al destruir la forma argumentativa y presentar la discusión en forma de un teatro carnavalizado. Es como si no quedara logos en pie, sólo voces desmitificadoras y palabras fragmentadas en un presente lleno de incertidumbre. Sánchez Mejías no da respuesta a la muerte de una era y a la compleja relación entre la vida y la política de la modernidad. No construye nada (no "escalerita de palabras") para captar el futuro en un relato. Todos los textos tratados anteriormente destruyen el relato nacional, cada uno a su manera. Intentan, construir, sin embargo, paradójicamente un vacío que deja espacio para el yo, aquí, y ahora y “la inmediatez de la experiencia humana” (Prieto 79), desligado de la memoria, el sueño y los discursos sobre un futuro mejor. Sólo queda un presente, incierto, en que murieron los relatos. Una incertidumbre silenciosa sin significados.

BibliografíA

Agamben, Giorgio. Homo sacer, el poder soberano y la nuda vida. Valencia: Pre-Textos, 1998.

Araújo, Nara. “Erizar y divertir: la poética de Ena Lucía Portela”. Unión 42 (enero-marzo 2001): 22-31.

Benjamín, Walter. “Über den Begriff der Geschichte”. Gesammelte Schriften. Band I.2 Frankfurt am Main: Suhrkamp Verlag, 1980. 691-704.

Caballero, Atilio. La última playa. La Habana: Ediciones Unión, 1998.

Cámara Betancourt, Madeline. "Feminismo vs totalitarismo: Notas para un estudio de textos y contextos de mujeres, en Cuba contemporánea (1989-1994)”. Bordes 2 (1995): 54-64.

Castro Ruz, Fidel. "Palabras a los intelectuales.” http ://www.min.cult.cu/historia/ palabrasalosintelectuales.html (1-5-2002)

"Speech at the $49^{\text {th }}$ anniversary of the attack on Moncada, 26 July 2002”. Granma. http://www.embacubalebanon.com/discurso26jul2002e.html (27-7-2002)

Castro Gómez, Santiago. Crítica de la razón latinoamericana. Barcelona: Puvill Libros, 1996.

Cohn, Dorrit. Transparent Minds. Narrative Modes for Presenting Consciousness in Fiction. Princeton: Princeton University Press, 1978.

Elbaz, Robert. Changing Nature of the Self: A Critical Study of the Autobiographic Discourse. London/Sydney: Croom Helm, 1988.

Eliade, Mircea. Myth and Reality [1963]. New York: Harper \& Row Publishers, 1975.

Foucault, Michel. “The Subject and Power”. Michel Foucault: Beyond Structuralism and Hermeneutics. Hubert y Paul Rabinow Dreyfus, eds. Chicago: University of Chicago Press, 1982.

Fornet, Jorge. “La narrativa cubana entre la utopía y el desencanto”. La Gaceta de Cuba. 5 (2001): 38-46. 
González Rey, Fernando. “Acerca de lo social y lo subjetivo en el socialismo”. Temas 3 (1995): 93-101.

Habermas, Jürgen. El discurso filosófico de la modernidad. Buenos Aires: Taurus, 1989. Hassan, Ihab. The Postmodern Turn. Essays in Postmodern Theory and Culture. Columbus: Ohio State University Press, 1987.

Jameson, Frederic. Postmodernism or, the Cultural Logic of Late Capitalism. Durham: Duke University Press, 1999.

Hernandez Busto, Ernesto. "Recuerdos de una vida dañada”. Letras Libres (julio 2004). Lacan, Jacques. Écrits. A selection. New York/London: W.W.Norton \& Company, 1977. Lyotard, François. La condition postmoderne: Rapport sur le savoir. Paris: Les Éditions de Minuit, 1979.

Mateo Palmer, Margarita. Ella escribía poscrítica. La Habana: Casa Editora Abril, 1995. Mosquera, Gerardo. "El síndrome de Marco Polo. Algunos problemas alrededor de arte y eurocentrismo”. Casa de las Américas 188 (1992): 64-70.

Ponte, Antonio José. "La fiesta vigilada”. Almanaque. Cuba y el día después, doce ensayistas nacidos con la revolución imaginan el futuro. Iván de la Nuez, ed. Barcelona: Mondadori, 2001. 23-36.

Portela, Ena Lucía. El pájaro: pincel y tinta china. La Habana: Ediciones Unión, 1998.

Prieto, Abel. “Calibán frente al discurso de la posmodernidad”. Casa de las Américas 186 (1992): 134-136.

Prieto, José Manuel. "Nunca antes habías visto el rojo”. Almanaque. Cuba y el día después, doce ensayistas nacidos con la revolución imaginan el futuro. Iván de la Nuez, ed. Barcelona: Mondadori, 2001. 73-80.

Redonet, Salvador. “Otro final promisorio: (post)novísimos y/ o qué?” Union VIII/22 (1996): 68-75.

Sánchez, José Miguel (Yoss). “La causa que refresca”. Nuevos narradores cubanos. Michi Strausfeld, ed. Madrid: Ediciones Siruela, 2000. 241-247.

Sánchez Mejías, Rolando. “Reunión”. Almanaque. Cuba y el día después. Doce ensayistas nacidos con la Revolución imaginan el futuro. Iván de la Nuez, ed. Barcelona: Mondadori, 2001. 199-228.

Sarduy, Severo. Escrito sobre un cuerpo. Buenos Aires: Editorial Sudamericana, 1969. Serrano, Pío. “Café Nostalgia de Zoé Valdés”. Revista Hispano Cubana 2 (1998): 3-6. Valdés, Zoé. La nada cotidiana. Madrid: Emecé, 1995.

Whitfield, Esther Katheryn. "Fiction(s) of Cuba in Literary Economies of the 1990s: Buying in or Selling out?” Dissertation. Harvard University, 2001. 